\title{
Avaliação da independência das agências reguladoras dos setores de energia elétrica, telecomunicações e petróleo no Brasil
}

\author{
José Nilton de Souza Vieira \\ Programa de Pós-Graduação em Administração (UnB) \\ Ricardo Corrêa Gomes \\ Universidade de Brasília (UnB)
}

Edson Ronaldo Guarido Filho

Universidade Federal do Paraná (UFPR)

Este artigo propõe novos parâmetros e indicadores para avaliar os níveis de independência formal e de facto dos órgãos reguladores. $\mathrm{O}$ alvo são as agências dos setores de eletricidade, telecomunicações e petróleo no Brasil. O estudo é orientado por duas perspectivas teóricas: a da necessidade de independência dos órgãos reguladores, uma vez que a interferência política pode elevar os riscos e inibir o investimento privado, especialmente nos setores de infraestrutura; e a da influência das instituições, presentes em cada setor e em cada país, sobre os novos desenhos institucionais. Trata-se de uma pesquisa descritiva, que identificou diferenças nos desenhos institucionais, não captadas por metodologias convencionais, como o índice de governança regulatória, proposto pelo Banco Mundial. Os resultados confirmam a maior resistência às mudanças nos setores de energia: menor independência formal das agências reguladoras e presença mais ativa das autoridades políticas no campo normativo desses setores. Além disso, os índices estimados confirmam que as três agências não dispõem de autonomia para gerir as próprias receitas. Essa limitação à independência de facto ocorre principalmente na fase de elaboração da proposta orçamentária.

Palavras-chave: agências reguladoras, autonomia administrativa, independência financeira

[Artigo recebido em 17 de outubro de 2018. Aprovado em 16 de outubro de 2019.] 
Evaluación de la independencia de las agencias reguladoras de los sectores de energía eléctrica, telecomunicaciones y petróleo en Brasil

Este artículo propone nuevos parámetros e indicadores para evaluar los niveles de independencia formal y de hecho de los órganos reguladores. El objetivo son las agencias de los sectores de electricidad, telecomunicaciones y petróleo en Brasil. El estudio se guía por dos perspectivas teóricas: La necesidad de independencia de los organismos reguladores, ya que la interferencia política puede aumentar los riesgos e inhibir la inversión privada, especialmente en los sectores de infraestructura; y la influencia de las instituciones presentes en cada sector y en cada país en los nuevos diseños institucionales. Esta es una investigación descriptiva que identificó diferencias en los diseños institucionales, no capturados por las metodologías convencionales, como el índice de gobierno regulatorio propuesto por el Banco Mundial. Los resultados confirman la mayor resistencia a cambios en los sectores de energía: menos independencia formal de las agencias reguladoras y una presencia más activa de las autoridades políticas en el campo regulatorio de estos sectores. Además, los índices estimados confirman que las tres agencias no disponen de autonomía para gestionar los propios ingresos. Esta limitación a la independencia de hecho ocurre principalmente en la fase de elaboración de la propuesta presupuestaria.

Palabras-clave: agencias reguladoras, autonomía administrativa, independencia financiera

\section{Assessment of the independence of regulatory agencies of the electric power, telecommunications and oil sectors in Brazil}

This article proposes new parameters and indicators to evaluate the levels of formal and de facto independence of regulatory bodies. The target is the agencies of the electricity, telecommunications and oil sectors in Brazil. The study is guided by two theoretical perspectives: the need for independence of the regulatory bodies, as political interference can increase risks and inhibit private investment, especially in infrastructure sectors; and the influence of institutions, present in each sector and in each country, on the new institutional designs. This is a descriptive research that identified differences in institutional designs not captured by conventional methodologies, such as the regulatory governance index proposed by the World Bank. The results confirm the greater resistance to changes in the energy sectors: less formal independence of regulatory agencies and more active presence of political authorities in the regulatory field of these sectors. Besides, the indexes confirm that the three agencies do not have autonomy to manage their revenues. This limitation on de facto independence occurs mainly at the stage of the budget proposal.

Keywords: administrative autonomy, financial independence, regulatory agencies 


\section{Introdução}

As décadas de 1980 e 1990 foram marcadas por importantes reformas na administração pública de diversos países da Europa e América Latina, que também contemplaram mudanças nos modelos de prestação dos serviços públicos (SMITH, 1997; Majone, 1998; LeVi-Faur, 2003; Christensen; LAegreid, 2005; Yesilkagit; CHRISTENSEN, 2010). A chamada transição do Estado Intervencionista para o Estado Regulador (MAJONE, 1998) é assentada em três pilares: privatização de empresas estatais; transferência da prestação dos serviços públicos para prestadores privados; e criação de agências reguladoras independentes, para regular e fiscalizar esses novos atores (SMITH,1997; MAJONE, 1998; TRILLAS; MONTOYA, 2013).

A criação de órgãos reguladores independentes tem o propósito de reduzir a interferência das autoridades políticas, conferindo maior segurança jurídica às decisões de investimento dos empreendedores privados, especialmente nos setores de infraestrutura (SMITH, 1997; MAJONE, 1998; GILARDI, 2002; TRILLAS; MONTOYA, 2013; Nunes; Nunes; Rego, 2015; PrAKASH; Potoski, 2016). A preocupação com a independência formal levou agências e organismos multilaterais a recomendarem um conjunto de requisitos que deveriam ser contemplados pelas leis de criação desses órgãos (ORgANISATION FOR ECONOMIC CO-OPERATION AND DEVELOPMENT, 1997, 2005). A aderência dos novos marcos legais a tais requisitos passou a ser avaliada por meio de diversos índices, em especial o índice de independência formal (IIF) (GILARDI, 2002) e o índice de governança regulatória (IGR) (CORREA; PEREIRA; MUeLLeR; Melo, 2006, 2017).

A teoria institucional fornece subsídios para compreender que esses novos marcos legais podem não ser suficientes para proteger os órgãos reguladores contra a interferência externa, seja das autoridades políticas, ou dos regulados. 0 novo modelo implica a redução do protagonismo das autoridades políticas (SMITH, 1997; MAJONE, 1998), colidindo com a tendência de resistência das instituições às mudanças (MARCH; OLSEN, 1989; OSTROM, 1990; NORTH; 1991). A falta de efetividade das leis levaria a diferenças entre os níveis de independência formal e de facto (MaggettI, 2007; Mahoney; Thelen, 2010; Gilardi; MAggetti, 2011; Nunes et al., 2015; PrAKASH; POTOSKI, 2016; GUARDIANCICH; GUIDI, 2016).

Essa preocupação com a efetividade dos desenhos institucionais está presente em diversos estudos também no Brasil (PAVÃo, 2008; Pó, 2009; Prado, 2010; BATISTA, 2010, 2011; DE BonIS, 2016, entre outros). O país foi um dos últimos da América Latina a aderir ao movimento de reforma regulatória (LEVI-FAUR, 2003; JORDANA; LEVI-FAUR, 2005), com a criação das primeiras agências reguladoras federais somente na segunda metade da década de 1990. 
Tais processos foram caracterizados por importantes diferenças dos níveis de mobilização dos atores em cada setor (FARIAS; RIBEIRO, 2002; VELASCO JUNIOR, 2005; PAVÃo, 2008). As divergências entre os interesses dos Poderes Executivo e Legislativo (COSTA, 2002; PAVÃo, 2008) e a concentração de poderes na Presidência da República (Pereira; Mueller, 2000; Ames, 2001; Prado, 2008, 2010) também contribuem para explicar a baixa efetividade dos desenhos institucionais, constatada por Batista (2010, 2011).

Posteriormente, a chegada do Partido dos Trabalhadores ao poder, em 2003, trouxe importantes mudanças na orientação política do governo, o que se reproduziu na tentativa de alterar as relações entre o Poder Executivo e os órgãos reguladores (BRASIL, 2003; SANTOS; 2005; CUNHA; ROdRIGO, 2012; CUNHA, 2016).

Diante disso, este artigo reexamina as leis de criação das três primeiras agências reguladoras (Agência Nacional de Energia Elétrica - Aneel, Agência Nacional de Telecomunicações - Anatel e Agência Nacional do Petróleo - ANP), com o propósito de identificar e caracterizar diferenças do nível de independência não captadas por índices como o IIF e o IGR. Ele também examina a produção normativa das autoridades políticas nos três setores e constrói dois indicadores para avaliar a independência financeira das agências reguladoras.

Após essa introdução, é apresentada a fundamentação teórica. Os procedimentos metodológicos são descritos na sequência. A última seção traz os resultados preliminares, confirmando a maior independência formal da Anatel e concluindo que as maiores limitações à independência financeira são impostas durante a fase de elaboração e aprovação das propostas orçamentárias.

\section{A fundamentação teórica}

A expressão reforma regulatória é amplamente utilizada para denominar o movimento de reformas empreendidas nos serviços públicos de diversos países a partir do final da década de 1970. O processo teve início nos Estados Unidos, em 1978, quando o Public Utilities Regulatory Policy Act permitiu a abertura do setor elétrico para a participação de geradores privados independentes (HORWITZ, 1989; LEVI-FAUR, 2003).

Nos países onde os serviços públicos ainda eram prestados diretamente pelo Estado, as reformas deveriam contemplar a privatização das Utilities, a remoção de barreiras legais à entrada de novos atores onde fosse possível a competição, e a criação de estruturas regulatórias especializadas e independentes (SMITH, 1997; THATCHER, 2002; LEVI-FAUR, 2003; CHRISTENSEN; LAEgREID, 2005; OLSEN, 2009; TRILLAS; MONTOYA, 2013; DUDLEY; WEGRICH, 2015). 
A transferência da prestação dos serviços para a iniciativa privada teria três motivações: lidar com a incapacidade do Estado para efetuar os investimentos necessários à modernização tecnológica e ao atendimento da demanda reprimida (MAJONE, 1998; TRILlAS; MontoyA, 2013); superar a ineficiência do Estado, especialmente devido ao seu crescimento excessivo (MAJONE, 1998; CHRISTENSEN; LAEGREID, 2005; YESILKAGIT; CHRISTENSEN, 2010); e, especialmente nos países em desenvolvimento, contribuir para o equilíbrio das contas públicas (BRESSER-PEREIRA, 2001; LEVI-FAUR, 2003; JORDANA; LEVI-FAUR, 2005; WORLD BANK, 2010).

Diante desse contexto, Smith (1997) destaca três atribuições dos órgãos reguladores independentes: proteger os usuários contra abusos de empresas com poder de mercado; proteger as empresas contra ações arbitrárias dos governos; e fomentar a eficiência econômica. Majone (1998) traz argumentos adicionais, aplicáveis aos setores de infraestrutura: evitar descontinuidades, que poderiam elevar a insegurança jurídica para os prestadores dos serviços; e retirar da classe política o ônus acarretado pela adoção de medidas desagradáveis (como cumprir cláusulas contratuais de reajustes tarifários).

Spiller e Tommasi (2003) enfatizam a necessidade de mecanismos formais de governança para evitar que as agências reguladoras sejam capturadas pelas autoridades políticas. Esses autores aprimoraram o modelo proposto por Levy e Spiller (1994), o qual subordina a capacidade de empreender mudanças intertemporais nas políticas públicas às instituições políticas de cada setor ou país. Tais mudanças parecem imprescindíveis, uma vez que o Estado Regulador tende a levar à perda de protagonismo das autoridades políticas, em benefício do fortalecimento das autoridades regulatórias (MAJONE, 1998).

Gilardi (2001) sublinha uma importante diferença entre a criação de órgãos reguladores e outros processos de delegação: a abordagem convencional de agência (MITNICK, 2013; EISENHARDT, 1989; GAILMARD, 2014) propõe uma relação direta entre meios de controle e nível de delegação; já o modelo de agências reguladoras baseia-se na premissa da credibilidade, o que exige a ausência desse controle, ou seja, a independência do agente (órgão regulador) em relação ao principal (autoridades políticas).

Essa preocupação é constatada quando se analisa a metodologia proposta pelo mesmo autor para estimar o índice de independência formal (IIF) (GILARDI, 2002). Esse índice contempla cinco dimensões: status do diretor-geral; status do conselho de administração; relacionamento do órgão regulador com o governo e com o Parlamento; autonomia financeira e organizacional; e competências regulatórias. Cada dimensão tem um peso de " 0,2 " e o índice pode variar entre " 0,00 " e " 1,00 ". Em síntese, na visão do autor, as autoridades regulatórias devem ser dotadas de 
poderes e recursos para assegurar a proteção às relações contratuais e para evitar que sejam capturadas pelas autoridades políticas (GILARDI, 2002, p. 883).

Um aspecto negativo do IIF é o fato de que ele não contém indicadores de transparência e accountability. A metodologia adotada pelo Banco Mundial para estimar o índice de governança regulatória (IGR) (CORREA et al., 2006 e 2017) traz avanços nessa direção, ao mensurar a permeabilidade. Ela evita que os dirigentes dos órgãos reguladores priorizem os próprios interesses (CALVERT MCCUBBINS; Weingast, 1989; KRAUSE; LeWIS; Douglas, 2006; TrILlaS; MontoyA, 2013), reduz os riscos de captura pelos regulados (LODGE, 2004; BOVENS, 2010; GAILMARD, 2014; DUDLEY; WEGRICH, 2016) e contribui para contornar as críticas à falta de legitimidade democrática (Bovens, 2010; MAggetTI, 2011; NunEs et al., 2015; Fung, 2015).

As atribuições desses órgãos variam em função dos desenhos institucionais adotados por cada país e para cada setor (MUELler; PEREIRA, 2002; LEVI-FAUR, 2003; SPILLER; TOMMASI, 2003). As preocupações quanto ao caráter estratégico tendem a preservar a maior competência decisória das autoridades políticas nos setores de energia (LEVI-FAUR, 2003; JORDANA; LEVI-FAUR, 2005). Além disso, conforme Gilardi e Maggetti, (2011), a institucionalização do novo modelo pode levar tempo, resultando em diferenças entre os níveis de independência formal (as garantias estabelecidas em lei) e de independência de facto (o respeito a essas garantias, especialmente por parte das autoridades políticas e dos regulados). Em função disso, eles propõem um conjunto de parâmetros para avaliar a efetividade da independência das agências reguladoras, tanto em relação às autoridades políticas, quanto em relação aos regulados (GILARDI; MAGGETTI, 2011, p. 205).

Conforme tendência internacional (LEVI-FAUR, 2003; JORDANA; LEVI-FAUR, 2005; JORDANA et al., 2011; MEDIANO, 2018), é esperada uma maior participação das autoridades políticas nos processos decisórios do setor de energia. Ou seja, as agências do setor de telecomunicações normalmente são dotadas de maior independência formal. Entretanto, os processos de institucionalização tendem a levar à convergência entre independência formal e independência de facto, especialmente quando os resultados favoráveis levam ao aumento da confiança dos diferentes grupos de atores no novo desenho institucional (GILARDI ; MAGGETTI, 2011).

De todo modo, a estabilidade das regras é fundamental para a consolidação do novo desenho institucional (MACEY, 1992; GILARDI, 2002; TRILLAS; MONTOYA, 2013; FALCÃO-MARTINS, 2014). Esse é outro fator de preocupações no Brasil, caracterizado pela concentração de poderes na Presidência da República, (PEREIRA; MUELLER, 2000; AMES, 2001; PRADo, 2008, 2010), o que pode facilitar a atuação normativa do Poder Executivo em caso de perturbações nos ambientes regulados (edição de medidas provisórias, por exemplo). 
Além disso, há controvérsias jurídicas em relação ao alcance dessa delegação, uma vez que a Constituição brasileira coloca todos os órgãos da administração pública federal subordinados ao Presidente da República. Logo, a própria autonomia dos órgãos reguladores para gerir as receitas com taxas de fiscalização passa a ser objeto de contestação (PESSOA, 2007; PRADO, 2008; DeBUS, 2010).

Alguns autores já avançaram na investigação das diferenças entre independência formal e independência de facto das agências reguladoras brasileiras. Pavão (2008), por exemplo, ao estudar os setores elétrico e de telecomunicações, constatou um importante paradoxo: embora os índices de governança regulatória estimados por Correa et al. (2006) fossem relativamente altos, as duas agências estavam fortemente sujeitas à ingerência política (controle orçamentário, atraso na indicação dos diretores e, no caso da Aneel, eventuais restrições associadas aos contratos de gestão). Por outro lado, Pó (2009) concluiu que, apesar do baixo nível de independência de facto, as relações contratuais com as concessionárias e a autonomia das agências reguladoras para procederem às revisões tarifárias nesses mesmos setores foram mantidas, ainda que por meio de decisões das instâncias superiores do Judiciário.

Batista (2010), por sua vez, desenvolveu e estimou o índice de interferência política (IIP), por meio do qual essa autora avaliou o uso, pelo Poder Executivo federal, de três instrumentos de intervenção discutidos por Pavão (2008): contingenciamento orçamentário; pressões para que diretores deixassem os cargos antes da conclusão dos mandatos; e atraso nas indicações de novos diretores. Posteriormente, ela comparou o IIP com o IIF das dez agências reguladoras federais brasileiras e constatou uma relação direta entre eles, ou seja, uma relação inversa entre independência formal e independência de facto. Os resultados corroboraram os achados de Pavão (2008), quanto à resistência por parte do Poder Executivo em aceitar os desenhos institucionais aprovados pelo Congresso Nacional (BATISTA, 2011).

Este artigo pretendeu avançar nesse campo, examinando os níveis de independência formal e de facto das três agências reguladoras a partir de alguns parâmetros que permitem avaliar os dois atributos que sintetizam as preocupações de Gilardi (2001) e são também destacados por Gilardi e Maggetti (2011): poderes e recursos. Os poderes podem ser expressos por meio das competências regulatórias e da autonomia para exercê-las, o que inclui a autonomia administrativa e de gestão. Os recursos, por sua vez, estão associados à dotação de meios para o exercício dessas competências, especialmente a autonomia para arrecadar e gerir as receitas próprias. 


\section{Procedimentos metodológicos}

Este estudo tem o propósito de avançar na compreensão das diferenças entre os níveis de independência formal e de facto das agências reguladoras brasileiras em relação às autoridades políticas. $O$ foco foram as três agências que marcaram o início do processo de reforma regulatória no país: Aneel, Anatel e ANP. Para estimar a independência formal, utilizou-se o índice de independência formal (IIF), criado por Gilardi (2002) ${ }^{1}$. Já a independência de facto foi estimada a partir da revisão de alguns dos escores do IIF, conforme parâmetros propostos por Gilardi e Maggetti (2011).

A estimação do IIF foi feita a partir da análise do conteúdo das leis de criação das três agências, levando em conta os textos em vigor no final de 2017. As análises permitiram caracterizar diferenças relevantes nos textos legais, não captadas adequadamente pela escala proposta por Gilardi (2002) para alguns indicadores. Essa caracterização, apresentada no Apêndice $A$, embasou a atribuição de alguns dos escores, de forma a melhor refletir tais diferenças, como é o caso da dimensão "competências regulatórias" 2 .

O passo seguinte foi a estimação dos índices de independência de facto. Para tanto, tomou-se como referência os parâmetros propostos por Gilardi e Maggetti (2011, p. 205). Como alguns desses parâmetros já foram objeto de estudos anteriores, este estudo incorporou as contribuições de Pó (2009), Batista (2011) e De Bonis (2016) e avançou em dois aspectos: a revisão da metodologia para avaliar a independência financeira e a análise da atuação das autoridades políticas no campo normativo.

A independência financeira foi avaliada a partir de dois parâmetros: a magnitude das fontes próprias de recursos e a capacidade de gestão sobre essas fontes. Os dados sobre arrecadação e execução orçamentária foram obtidos a partir dos portais do Sistema Integrado de Planejamento e Orçamento (Siop), do Ministério

\footnotetext{
${ }^{1}$ Esse índice é composto por 21 indicadores, distribuídos em cinco dimensões: status do diretor-geral da agência; status do conselho de administração; relacionamento com o governo e com o parlamento; autonomia financeira e organizacional; e competências regulatórias. Os escores dos indicadores podem variar entre " 0,00 " e "1,00", conforme o nível de aderência à escala proposta pelo autor. Cada dimensão tem peso " 0,20 " e o índice é obtido a partir da soma dos escores dessas dimensões.

${ }^{2}$ Em relação a essa dimensão, Gilardi (2002) propõe cinco categorias: a maior independência (escore “1,00") significa que as competências regulatórias seriam exercidas exclusivamente pela agência. No outro extremo, “0,00" significaria que a agência teria apenas competências executivas. Os níveis intermediários $(0,75 ; 0,50$ e 0,25 ) representariam o compartilhamento com outras agências independentes, com o Parlamento e com o Poder Executivo, respectivamente. Logo, o ajuste nos escores teve o propósito de destacar diferenças nos níveis de compartilhamento dessas competências, expressas pela diferença da produção normativa das autoridades políticas (número de leis, medidas provisórias e decretos editados).
} 
do Planejamento, da Transparência (Controladoria-Geral da União) e Siga Brasil (Senado Federal). Além disso, foi utilizado o sistema "e-SIC" (Sistema Eletrônico do Serviço de Informações ao Cidadão), para solicitar esclarecimentos junto às próprias agências sobre a execução orçamentária e as metodologias utilizadas para contabilizar as receitas próprias.

As séries históricas de 1998 a 2017 possibilitaram construir, estimar e avaliar o comportamento de dois índices: o índice de autonomia orçamentária (IAO), obtido por meio da relação entre a despesa autorizada (LOA \pm créditos) e as receitas próprias; e o índice de execução orçamentária (IEO), que é uma relação entre recursos empenhados e a despesa autorizada (LOA \pm créditos). Os resultados das estimações estão no Apêndice B. Eles serviram de base para a revisão dos escores do indicador que trata das fontes de recursos, associado à dimensão "autonomia financeira e organizacional" do IIF.

O IAO avalia as limitações impostas às agências na gestão dos recursos próprios, ainda na fase de elaboração do orçamento. Essas limitações são impostas pelo Poder Executivo na fase de elaboração da proposta orçamentária e precisam ser referendadas pelo Legislativo, quando da aprovação da Lei de Diretrizes Orçamentárias (LDO) e da Lei Orçamentária Anual (LOA). O IEO, por sua vez, contempla a fase de execução orçamentária e permite verificar o alcance de eventuais contingenciamentos impostos pelo Poder Executivo.

Esses índices trazem dois avanços em relação à metodologia adotada por Batista (2010) para avaliar o contingenciamento orçamentário. O primeiro está relacionado à despesa autorizada: foram consideradas apenas as despesas obrigatórias e discricionárias, ou seja, foram subtraídos os valores da rubrica "reserva de contingência". Tal procedimento decorre do fato de que os recursos dessa rubrica não estão disponíveis para a programação orçamentária.

O segundo diz respeito ao tratamento dado para a receita arrecadada: foram considerados apenas os valores associados às fontes próprias de recursos previstas em lei, ou seja, foram excluídos os valores que cabem à União, como as receitas com outorgas de concessões e remuneração pelo uso de bens públicos. Com isso, foi possível mensurar o nível de autonomia das agências para gerirem as receitas próprias, bem como identificar em que momento as restrições à independência financeira são mais efetivas: se na hora da elaboração da proposta orçamentária ou na hora da execução do orçamento.

No caso específico da ANP, foi identificado um problema adicional, uma vez que essa agência não dispõe de dados sobre a receita arrecadada no período anterior a 2008. Além disso, os dados informados para o período de 2008 a 2011 pareciam não ter contemplado as receitas com participações especiais, nos 
termos do artigo 50 da Lei no 9.478, com redação dada pela Lei no 10.848/2004. Com isso, as receitas do período de 2000 a 2011 foram estimadas com base no disposto nos artigos 15, 16 e 50 da Lei no 9.478/1997 e os valores publicados nos anuários estatísticos da agência.

Para avaliar a atuação das autoridades políticas no campo normativo, foi feito o inventário das leis e decretos de cada setor, editados no desenho institucional anterior e no iniciado com as reformas regulatórias. Inicialmente, foram identificadas as normas que marcaram o início das reformas regulatórias setoriais. O estudo dessas normas permitiu identificar as normas que deram origem aos desenhos institucionais anteriores, caracterizados pela concentração das políticas setoriais no âmbito do Governo Federal. Em seguida, foi feito o inventário das leis e decretos em cada setor, ao longo dos períodos analisados.

No setor elétrico, o marco inicial da reforma foi a Lei no 8.631/1993, que estabeleceu o novo modelo tarifário. O marco inicial do desenho anterior foi o Código de Águas (Decreto-Lei no 24.643/1934). Nos outros dois setores, as reformas se iniciaram com as emendas constitucionais de 1995, que flexibilizaram o monopólio estatal. No setor de petróleo, o desenho institucional anterior teve início com a criação do Conselho Nacional do Petróleo (Decreto-Lei no 395/1938). Já no setor de telecomunicações, o desenho anterior teve início com a criação do Conselho Nacional de Telecomunicações (Decreto no 50.666/1961).

Foram inventariados um total de 199 leis/decretos-lei e 301 decretos, distribuídos por setor e por período, o que permitiu comparar a frequência dessa produção normativa antes e a partir do início das reformas regulatórias. O objetivo foi verificar se, dada a premissa da estabilidade do ambiente legal como condição para atrair o investimento privado, a delegação de competências regulatórias para as agências teria levado à redução da atuação das autoridades políticas no campo normativo.

Também foi investigada a forma de iniciação do processo legislativo das leis promulgadas a partir do início das reformas regulatórias. O objetivo foi verificar a frequência da edição de medidas provisórias, fator relevante para analisar a ascendência do Poder Executivo no campo normativo, conforme apontam Pereira e Mueller (2000) e Prado (2010).

A análise da produção normativa embasou a revisão dos escores da dimensão "competências regulatórias" do IIF. Os ajustes decorrem da constatação de que a diferença do nível de frequência da produção normativa das autoridades políticas nos três setores não é adequadamente captada pelos parâmetros propostos por Gilardi (2002) para avaliar o nível de independência dos órgãos reguladores em relação a essa dimensão. 
Esses ajustes nos escores dos indicadores associados às dimensões "autonomia financeira e organizacional" e "competências regulatórias" permitiram chegar a resultados aproximados do "índice de independência de facto", tendo em conta a metodologia proposta por Gilardi (2002), para estimar a independência formal. Os resultados das estimações dos dois índices são apresentados no Apêndice C.

\section{Analisando a independência formal e de facto}

Os processos de reforma regulatória aqui estudados tiveram início pelo setor elétrico, com a aprovação da Lei no 8.631/1993, que estabeleceu o novo regime tarifário. O foco do Governo Federal era a eliminação dos subsídios cruzados, tido como indispensável para o fomento à competição no segmento de geração de energia. Nos outros dois setores, os processos exigiram a aprovação de três emendas constitucionais em 1995 (EC n 6, EC no 8 e EC $n$ ㅇ 9), que flexibilizaram o monopólio estatal na prestação de tais serviços.

Ainda em 1995, a Lei no 8.987 trouxe novas regras para os regimes de concessão e permissão para a prestação de serviços públicos. Na sequência, foram aprovadas as leis de reestruturação dos três setores e de criação das três agências reguladoras: Aneel (Lei no 9.427/1996), Anatel (Lei no 9.472/1997) e ANP (Lei no 9.478/1997). Apesar de fazerem parte do mesmo processo de reforma regulatória, é possível constatar importantes diferenças nos níveis de independência formal e de facto dessas agências. Essas diferenças são analisadas a seguir.

\subsection{Aspectos relevantes da independência formal}

As reformas regulatórias brasileiras já foram tema de diversos estudos ${ }^{3}$. Aqui, o objetivo foi avançar na caracterização das semelhanças e diferenças dos desenhos institucionais das três agências reguladoras a partir de cinco categorias: alcance e estabilidade das competências; autonomia administrativa e de gestão; autonomia financeira; autonomia de pessoal; e fontes de recursos. Essas categorias estão diretamente relacionadas com as dimensões "autonomia financeira e organizacional" e "competências regulatórias", que integram o IIF (GILARDI, 2002).

\footnotetext{
${ }^{3}$ No âmbito do Governo Federal, cabe destacar os Cadernos de Reforma do Estado, publicados pelo Ministério da Administração e Reforma do Estado (MARE); os estudos setoriais, patrocinados pelo Banco Nacional de Desenvolvimento Econômico e Social (BNDES); e os estudos realizados no âmbito do Programa de Fortalecimento da Capacidade Institucional para Gestão em Regulação, sob a coordenação da Casa Civil da Presidência da República. Há também estudos patrocinados pela iniciativa privada (em especial, a Confederação Nacional da Indústria - CNI e a Federação das Indústrias do Estado de São Paulo - FIESP) e por organismos multilaterais, como a OCDE e o Banco Mundial, que se somam a diversos trabalhos acadêmicos (teses, dissertações e artigos científicos).
} 
A comparação dos textos legais permitiu concluir que as três agências se encontram em situação semelhante apenas em relação à autonomia de pessoal, ou melhor, à falta dessa autonomia. Essa conclusão é reforçada por dois aspectos. $\mathrm{O}$ primeiro é que os projetos de lei, propondo a criação de novos cargos e as alterações na remuneração dos servidores, devem ser encaminhados ao Congresso Nacional pelo chefe do Poder Executivo.

O segundo é que a realização de concursos para o preenchimento de cargos vagos requer a aprovação do órgão central, responsável pela política de recursos humanos no âmbito do Poder Executivo. Esse problema deve persistir, tendo em vista o disposto pela Lei Geral das Agências Reguladoras, a Lei no 13.848/2019. Conforme o $\S 20$ do art. 3 을 dessa lei, as agências reguladoras precisam solicitar ao Ministério da Economia autorização para realizar concursos públicos, para prover os cargos já autorizados em lei e para alterar seus quadros de pessoal.

A análise dos dispositivos que tratam das demais categorias permitiu concluir que a Anatel foi dotada de maior nível de independência formal. Essa agência recebeu competências mais amplas e elas são mais estáveis, especialmente se comparadas com a Aneel. Essa última agência compartilha responsabilidades com o Conselho Nacional de Política Energética (CNPE), o Ministério de Minas e Energia (MME) e o Operador Nacional do Sistema (ONS). Além disso, ela teve suas competências alteradas com a crise hídrica de 2001 e com a mudança na orientação política do governo em 2003. Já a ANP recebeu competências atípicas (representar os interesses da União nos contratos de concessão), mas não tem autonomia para gerir dois importantes instrumentos regulatórios: a definição das alíquotas da Contribuição de Intervenção no Domínio Econômico (Cide) sobre combustíveis e dos percentuais de mistura dos biocombustíveis aos combustíveis fósseis.

Do ponto de vista da autonomia administrativa e financeira, a Lei $n=9.472$ foi mais incisiva ao estabelecer que a Anatel teria autonomia administrativa e de gestão, além da competência para arrecadar e gerir as receitas próprias. A Aneel,, por sua vez, tem sua autonomia limitada pela obrigatoriedade da celebração de contratos de gestão. De comum, as duas agências têm como principal fonte de receitas as taxas de fiscalização dos serviços regulados.

A ANP encontra-se numa situação mais vulnerável. A Lei no 9.478 até trouxe a previsão de fontes de receitas para essa agência, mas não definiu o percentual de participação nas receitas com os bônus de assinatura dos contratos de concessão e com as participações especiais. Em 2004, a Lei no 10.848 estabeleceu que essa agência receberia $70 \%$ das receitas com participações especiais destinadas ao MME (40\% das receitas pertencentes à União eram destinadas a esse ministério). Entretanto, esse dispositivo foi revogado em 2012, ocasião em que a Lei $\mathrm{n}$ o 
12.783 passou a destinar a totalidade desses recursos para o fundo social criado para receber os recursos provenientes da exploração de petróleo sob o regime de partilha. Com isso, a principal fonte própria está relacionada às receitas com pagamentos pela ocupação e retenção de áreas de exploração, mas a arrecadação é inferior à despesa autorizada, o que coloca essa agência como dependente do Tesouro Nacional.

Essa caracterização das diferenças entre as três agências, apresentada no Apêndice $A$, embasou a atribuição dos escores para os indicadores, de forma a refletir as diferenças dos níveis de independência formal que não seriam captadas adequadamente pela metodologia original do IIF. Os escores de todos os indicadores são apresentados no Apêndice $C$, que também traz a estimativa do índice de independência de facto. A síntese, contendo a consolidação dos resultados das cinco dimensões, é apresentada mais adiante.

\subsection{Aspectos relevantes da independência de facto}

Conforme abordado anteriormente, ao longo dos últimos anos diversos pesquisadores têm se dedicado à investigação dos instrumentos por meio dos quais as autoridades políticas podem limitar a independência de facto das agências reguladoras (GILARDI; MAGGETTI, 2011; NUNES ET AL., 2015; GUARDIANCICH; GUIDI, 2016; PRAKASH; РОTOSKY, 2016; entre outros). Essa preocupação com a efetividade dos desenhos institucionais também está na agenda de pesquisas no Brasil (CORREA et al., 2006 e 2017; PAVÃo, 2008; Pó, 2009; BATISTA, 2010, 2011; CUNHA; RodRIGo, 2012; DE BONIS, 2016).

Este estudo procurou avançar em dois aspectos ainda pouco explorados. O primeiro é a análise da produção normativa das autoridades políticas (edição de leis e decretos), um importante parâmetro para avaliar a evolução na direção da institucionalização do novo desenho. O segundo é a estimação da independência financeira das agências reguladoras, outro fator que pode afetar o exercício das atividades regulatória e fiscalizatória. Os resultados são apresentados a seguir.

\subsubsection{Sobre a produção normativa das autoridades políticas}

A pesquisa documental nos sítios da Presidência da República, da Câmara dos Deputados e do Senado Federal, na internet, permitiu identificar o conjunto de leis e decretos associados a cada desenho institucional (o anterior e o construído a partir das reformas regulatórias) nos três setores. Os resultados, expressos na Tabela 1, evidenciam a alta produção normativa das autoridades políticas após o início das reformas regulatórias. 
Os números confirmam a tendência de maior participação das autoridades políticas nos processos decisórios dos setores de energia (LEVI-FAUR, 2003; JORDANA et al., 2011; MEDIANo, 2018). Além disso, o elevado número de decretos e medidas provisórias reforça a preocupação quanto ao risco de instabilidade do ambiente legal, em decorrência da excessiva concentração de poderes na Presidência da República (Pereira; Mueller, 2000; AMES, 2001; Prado, 2008, 2010).

Também foi possível constatar que alguns fatores intervenientes estimularam o aumento dessa produção normativa: edição de 8 MPs e 15 decretos, para lidar com o racionamento de energia provocado pela crise hídrica de 2001; edição de 15 MPs e 27 decretos nos dois primeiros anos de governo do Partido dos Trabalhadores; e edição de 17 decretos alterando a carga tributária sobre os combustíveis, em decorrência das flutuações das cotações do petróleo no mercado internacional.

Tabela 1 - Número de normas relacionadas aos setores de energia elétrica, telecomunicações e petróleo, editadas antes e depois das reformas regulatórias

\begin{tabular}{lccc}
\hline Tipo de norma & $\begin{array}{c}\text { Setor } \\
\text { elétrico }\end{array}$ & $\begin{array}{c}\text { Setor de } \\
\text { telecomunicações }\end{array}$ & $\begin{array}{c}\text { Setor de } \\
\text { petróleo }\end{array}$ \\
\hline $\begin{array}{l}\text { Anteriores às reformas } \\
\text { regulatórias }\end{array}$ & 94 & 38 & 99 \\
\hline $\begin{array}{l}\text { Emendas constitucionais } \\
\text { Leis/Decretos-lei }\end{array}$ & 36 & 1 & - \\
\hline Decretos & 58 & 19 & 43 \\
\hline $\begin{array}{l}\text { Associadas às reformas } \\
\text { regulatórias' }\end{array}$ & 144 & 18 & 56 \\
\hline Emendas constitucionais & - & 44 & 85 \\
\hline Leis & 49 & 1 & 41 \\
\hline Forma de iniciação & 12 & 11 & 21 \\
\hline Projetos de lei & 37 & 9 & 20 \\
\hline $\begin{array}{l}\text { Medidas provisórias (MPs) } \\
\text { Decretos }\end{array}$ & 95 & 32 & 42 \\
\hline $\begin{array}{l}\text { Fonte: Legislação brasileira. Disponivel em <www.planalto.gov.br>. Elaboração própria. } \\
\text { (1) Entre o início das reformas e dezembro de 2017. }\end{array}$ & & & \\
\hline
\end{tabular}

Foi observada a maior estabilidade do ambiente legal do setor de telecomunicações. Apesar do aumento do número de decretos, dos 32 editados após o início da reforma regulatória, 19 foram editados entre 1995 e 2001, antes 
da estruturação da Anatel. Em 2001, vários desses decretos foram revogados e substituídos por regulamentos dessa agência. Além disso, dos treze decretos posteriores a 2002, seis dispõem sobre a revisão das metas de universalização dos serviços públicos, em conformidade com a Lei no 9.472 .

Algumas normas dos setores de energia apresentaram alta instabilidade, cabendo destacar quatro delas. A Lei no 9.478/1997 sofreu 19 alterações (incorporou novas regras para a repartição dos royalties e participações especiais, e o novo modelo de exploração do petróleo, além das regras para arrecadação e distribuição das receitas com a Cide sobre combustíveis). A Lei no 9.427/1996 sofreu 13 alterações, algumas das quais restringindo as competências da Aneel. A Lei no 10.438/2002, que tratou da oferta emergencial de energia no racionamento de 2001 e do apoio às fontes alternativas, sofreu 15 alterações. O Decreto $n=5.163 / 2004$, que regulamentou a Lei no $10.848 / 2004$ no que diz respeito às novas regras para a comercialização de energia elétrica, sofreu 18 alterações.

Essa frequente alteração nas regras, especialmente por meio de decretos, parece limitar a capacidade das agências reguladoras em conferirem segurança jurídica para os demais atores. Em função disso, essa foi uma variável utilizada como proxy para avaliar o nível de independência de facto das agências na dimensão "competências regulatórias", embasando os ajustes nos escores em relação à independência formal.

\subsubsection{Sobre a independência financeira das agências reguladoras}

A existência de fontes próprias de recursos é destacada tanto no IFF (GILARDI, 2002) quanto no IGR (CORREA et al., 2006, 2017) como um dos requisitos indispensáveis para que os órgãos reguladores possam desempenhar suas atribuições com independência em relação às autoridades políticas.

Entretanto, conforme a sistemática do processo orçamentário brasileiro, pode haver uma significativa diferença entre receitas próprias e despesa autorizada, mesmo quando se trata de receitas vinculadas, como as taxas de fiscalização. Ademais, o Poder Executivo pode editar decretos de contingenciamento e portarias fixando limites para a programação orçamentária. Diante disso, este estudo procurou identificar em que momento as agências reguladoras sofrem maiores restrições à sua independência financeira: se na hora de elaborar ou na hora de executar a proposta orçamentária. Para tanto, foram construídos e estimados dois índices (IAO e IEO). As estimações compreenderam o período de 1998 a 2017 e os resultados estão no Apêndice $B$.

Os resultados do IAO permitiram concluir que os orçamentos autorizados da Aneel e, principalmente, da Anatel, não acompanharam o crescimento das receitas 
próprias. No período estudado, o orçamento autorizado da Aneel correspondeu, em média, a 60,9\% e o da Anatel a 33,5\% das receitas próprias. Entretanto, quando se analisam apenas os 10 últimos anos, essa restrição torna-se maior: enquanto o índice da Aneel cai para $56 \%$, o da Anatel cai para apenas $16,5 \%$. Houve um pequeno aumento dos índices em 2016 e 2017, mas em decorrência da retenção de $30 \%$ dessa receita arrecadada, por força da Emenda Constitucional no 93/2016, que trata da Desvinculação das Receitas da União (DRU) para o período de 2016 a 2023.

Em relação à ANP, a instabilidade das fontes próprias levou a grandes flutuações no índice: baixo entre 2004 e 2011 (média de 24,5\%) e alto nos períodos anterior e posterior (média de 121,2\%), inclusive com as receitas próprias abaixo da despesa autorizada, caracterizando a dependência da agência em relação ao Tesouro Nacional.

Do outro lado, foi confirmada a tendência ao aumento da execução orçamentária das três agências, conforme demonstrado pelo IEO. No período estudado, a execução média da Aneel foi de $80,8 \%$, ao passo que a da ANP foi de $75,4 \%$ e a da Anatel foi de $74,7 \%$. Entretanto, ao analisar apenas os últimos dez anos, os três índices subiram: o da Aneel para $84,4 \%$, o da ANP para $82,8 \%$ e o da Anatel para $87,4 \%$.

Cabe destacar que essa diferença em relação aos índices de contingenciamento apurados por Batista (2010) é explicada pela diferença nas metodologias. O IEO não considera os valores da rubrica reserva de contingência, ou seja, ele mede a taxa de execução das despesas efetivamente autorizadas pela lei orçamentária. Essa tendência de aumento da execução nas três agências sugere a redução da importância dos decretos e portarias de contingenciamento.

Por último, a análise estatística permitiu constatar a correlação negativa entre os dois índices para as três agências reguladoras. Essa correlação é mais acentuada para a Anatel $(-0,878)$ e para a $\operatorname{ANP}(-0,602)$ e mais moderada para a Aneel $(-0,188)$. Ou seja, as maiores limitações à autonomia das agências para gerirem as receitas próprias são impostas durante a elaboração e aprovação das propostas orçamentárias. Entretanto, cabe relembrar que o IAO da ANP é contaminado pela imprecisão dos números informados pela própria agência, em especial no que diz respeito ao tratamento dado para as receitas com participações especiais entre 2004 e 2012.

\subsection{Comparando independência formal com independência de facto}

As seções 4.1 e 4.2 embasaram a estimação dos dois índices (de independência formal e de independência de facto) das três agências reguladoras. Os resultados são apresentados no apêndice C. A Tabela 2 traz uma síntese, com os escores das cinco dimensões. 
Tabela 2 - Resultados do IIF e do índice de independência de facto

\begin{tabular}{|c|c|c|c|c|c|c|c|}
\hline \multirow[t]{2}{*}{ Dimensão } & \multirow[t]{2}{*}{ Pesos } & \multicolumn{3}{|c|}{$\begin{array}{l}\text { Índice de independência } \\
\text { formal atual revisado }\end{array}$} & \multicolumn{3}{|c|}{$\begin{array}{l}\text { Índice de independência } \\
\text { de facto }\end{array}$} \\
\hline & & Aneel & Anatel & ANP & Aneel & Anatel & ANP \\
\hline $\begin{array}{l}\text { Status do } \\
\text { diretor-geral da } \\
\text { agência }\end{array}$ & 0,20 & 0,144 & 0,151 & 0,144 & 0,144 & 0,151 & 0,144 \\
\hline $\begin{array}{l}\text { Status do } \\
\text { conselho de } \\
\text { administração }\end{array}$ & 0,20 & 0,144 & 0,151 & 0,144 & 0,144 & 0,151 & 0,144 \\
\hline $\begin{array}{l}\text { Relacionamento } \\
\text { com o governo } \\
\text { e com o } \\
\text { Parlamento }\end{array}$ & 0,20 & 0,083 & 0,167 & 0,150 & 0,083 & 0,167 & 0,150 \\
\hline $\begin{array}{l}\text { Autonomia } \\
\text { financeira e } \\
\text { organizacional }\end{array}$ & 0,20 & 0,117 & 0,200 & 0,092 & 0,067 & 0,067 & 0,067 \\
\hline $\begin{array}{l}\text { Competências } \\
\text { regulatórias }\end{array}$ & 0,20 & 0,050 & 0,150 & 0,100 & 0,050 & 0,150 & 0,050 \\
\hline IIF TOTAL & 1,00 & 0,538 & 0,819 & 0,630 & 0,488 & 0,685 & 0,555 \\
\hline
\end{tabular}

Fonte: elaboração própria, conforme metodologia proposta por Gilardi (2002).

Os dois índices coincidem para as três primeiras dimensões, o que significa a efetividade das leis de criação das três agências quanto a elas. Os escores mais elevados da Anatel nas duas primeiras dimensões são explicados pelo maior tempo de mandato de seus diretores (cinco anos, contra quatro das outras duas agências). Além disso, a dimensão "relacionamento com o governo e com o Parlamento" reflete a maior autonomia da Anatel (escore mais alto) e a obrigatoriedade de celebração de contratos de concessão imposta à Aneel (escore mais baixo).

As principais diferenças entre independência formal e de facto foram constatadas na dimensão "autonomia financeira e organizacional". Constatouse a ausência de autonomia financeira e a baixa autonomia organizacional (especialmente em relação à política de recursos humanos) das três agências. Logo, houve um maior rebaixamento do escore da Anatel, cuja lei de criação é mais incisiva ao tratar dessa autonomia.

Por último, a produção normativa das autoridades políticas embasou os escores das três agências na dimensão "competências regulatórias". A alta produção normativa nos setores elétrico e de petróleo fundamentam os escores mais baixos 
para a Aneel e a ANP. Do outro lado, a maior estabilidade do ambiente legal do setor de telecomunicações fundamentou o escore mais elevado para a Anatel. Destaquese que não foi considerada a forma de compartilhamento (se com o Executivo ou o Legislativo), mas a quantidade de normas editadas.

\section{Considerações finais}

Este estudo procurou identificar e explicar diferenças nos níveis de independência formal e de facto das três agências reguladoras que marcaram o início da reforma regulatória no Brasil: Aneel, Anatel e ANP. A referência para as análises foi o conjunto de indicadores que integram o IIF, criado por Gilardi (2002). As contribuições teóricas consistem no aprimoramento da metodologia para avaliar o contingenciamento orçamentário e na incorporação de um novo parâmetro para avaliar a interferência das autoridades políticas na independência de facto: a produção normativa.

A investigação permitiu concluir que o legislador foi mais incisivo ao tratar das atribuições e da autonomia administrativa e financeira da Anatel. Além disso, foi possível constatar que algumas diferenças entre as agências não são adequadamente captadas por índices usuais, como IIF. Por exemplo, esse índice apresenta resultados semelhantes para indicadores como "fontes do orçamento" e "competências regulatórias", porque não considera a magnitude das fontes próprias, nem a amplitude dessa delegação de competências. Em função disso, a análise de conteúdo das leis embasou os ajustes em alguns dos escores, para melhor refletir as diferenças nos níveis de independência formal.

Em se tratando da comparação entre independência formal e de facto, constatouse que a maior diferença está relacionada à dimensão "autonomia financeira e organizacional". O comportamento dos dois índices estimados (IAO e IEO) permitiu concluir que as maiores restrições à independência financeira da Aneel e da Anatel são impostas antes do encaminhamento das propostas orçamentárias ao Congresso Nacional. Os resultados indicam que a despesa autorizada não acompanha o crescimento da arrecadação, especialmente com as taxas de fiscalização. A ANP, por sua vez, encontra-se numa situação diversa: a ausência de fontes regulares de receitas a coloca como dependente de recursos do Tesouro Nacional.

Em se tratando da produção normativa, o grande número de medidas provisórias e decretos relacionados ao setor elétrico reforça a conclusão de que a amplitude da delegação de competências regulatórias para a Aneel foi menor. No caso da ANP, a frequente edição de normas alterando as alíquotas da Cide sobre combustíveis e os percentuais de mistura do etanol à gasolina embasaram a diferença nos escores dos índices de independência formal e de facto. 
Embora tenham sido constatados menores níveis de independência de facto, não foram encontradas evidências de discriminação contra agências cujo quadro diretivo não guardasse alinhamento com o Poder Executivo, preocupação presente nos estudos de Pavão (2008), Batista (2010) e De Bonis (2016). A mais frequente atuação das autoridades políticas no campo normativo dos setores de energia estaria associada à ocorrência de fatores intervenientes. A ausência de independência financeira, por sua vez, parece estar relacionada à crise fiscal, que inclusive motivou a aprovação da EC no 93/2016, estendendo a DRU até 2022.

Em suma, os níveis de independência de facto são menores. Entretanto, não é possível concluir que essas limitações impostas às agências reguladoras afetam o desempenho setorial, em especial, a segurança jurídica para que empreendedores privados tomem suas decisões de investimentos. Esse parece um importante campo para pesquisas futuras.

\section{Referências bibliográficas}

AMES, B. The deadlock of democracy in Brazil. Michigan: The University of Michigan Press, 2001. 288 p.

BATISTA, M. O desenho institucional em prática: uma análise da independência das agências reguladoras brasileiras (1997-2009). In: PRÊMIO SEAE - DEFESA DA Concorrência E Regulação EConômicA, 5., 2010, Brasília. Anais... Brasília: Seae, 2010.

BATISTA, M. Mensurando a independência das agências reguladoras brasileiras. Planejamento e Políticas Públicas, Brasília, DF, v. 36, p. 213-250, 2011.

BOVENS, M. Two concepts of accountability: accountability as a virtue and as a mechanism. West European Politics, v. 22, Issue 5, p. 946-967, 2010. Special issue: Accountability and European Governance.

BRASIL. Presidência da República. Análise e Avaliação do Papel das Agências Reguladoras no Atual Arranjo Institucional Brasileiro. Relatório de Grupo de Trabalho Interministerial. 2003. Disponível em: http://www.presidencia.gov.br/> Acesso em: 10 fev. 2017.

BRESSER-PEREIRA, L. C. Incompetência e confidence building por trás de 20 anos de estagnação na América Latina. Revista de Economia Política, São Paulo, v. 21, n. 1 (81), p. 141-166, jan.-mar. 2001.

CAlvert, R. L.; Mccubbins, M. D.; Weingast, B. R. A theory of political control and agency discretion. American Journal of Political Science, v. 33, n. 3, p. 588-611, ago. 1989.

Christensen, T.; LAEgREID, P. Regulatory reforms and agencification. Working Paper 6. Bergen: Stein Rokkan Centre for Social Studies, Unifob AS., nov. 2005. 
CORREA, P.; PEREIRA, C.; MUelleR, B.; Melo, M. Regulatorygovernance in infrastructure industries: assessment and measurement of Brazilian regulators. Washington, DC: The World Bank, 2006.

Correa, P.; Pereira, C.; Mueller, B.; Melo, M. Regulatory governance practice in Brazil: evolution and international benchmarking. Washington, DC: The World Bank, 2017. Unpublished paper.

CUNHA, B. Q. Antagonismo, modernismo e inércia: a política regulatória brasileira em três atos. Cadernos Ebape, Rio de Janeiro, Edição Especial, v. 14, p. 473-485, jul. 2016.

CUNHA, B. Q.; RODRIGO, D. Regulatory governance in Brazil: inconsistent coordination, institutional fragmentation and halfway reforms. BienniaL ECPR Standing Group for Regulatory Governance, Exeter, v. 4. p. 27-29, jun. 2012. Unpublished.

DEBUS, I. Agências reguladoras: aspectos relevantes da execução orçamentária, financeira e fontes de financiamento e análise de desempenho no período 19992009. Relatório de Consultoria. Pro-Reg, Casa Civil, Contrato 002/2010. Brasília, 2010.

DUDLEY, S. E.; WEGRICH, K. The role of transparency in regulatory governance: comparing US and EU regulatory systems. Journal of Risk Research, v. 19, Issue 9: Transparency Special Issue, p. 1141-1157, 2016-.

EISENHARDT, K. M. Agency theory: an assessment and review. Academy of Management Review, v.14, n. 1, p. 57-74, 1989.

FALCÃo-MARTINS, H. The exacerbation of meso policy: public policy formulation and regulatory activity in Brazil. In: IRSPM CONFERENCE, 18., Ottawa, 2014. Anais... Ottawa: IRSPM, 2014.

FARIAS, P. C. L.; RIBEIRO, S. M. R. Regulação e os novos modelos de gestão no Brasil. Revista de Serviço Público, Brasília, DF, Ano 53, v. 3, jul-set. 2002.

Fung, A. Putting the public back into governance: the challenges of citizen participation and its future. Public Administration Review, v. 75, Issue 4, 2015, p. 513-522.

GAILMARD, S. Accountability and principal-agent models. In: Bovens, M.; GoOdIN, R. E.; SCHILlEMANS, T. (Eds.). Oxford Handbook of Public Accountability. Oxford: Oxford University Press, ago. 2014. Cap. 6.

GILARDI, F. Principal-agent models go to Europe: independent regulatory agencies as ultimate step of delegation. In: ECPR General CONFERENCE, Canterbury (UK), 6-8 September 2001, Panel 11-8: Principal-Agency Institutional Relations. Anais... Canterbury: ECPR, 2001.

GILARDI, F. Policy credibility and delegation to independent regulatory agencies: a comparative empirical analysis. Journal of European Public Policy, London, v. 9, n. 6, p. 873-893, 2002. DOI: 10.1080/1350176022000046409.

GILARDI, F.; E MAGGETTI, M. The independence of regulatory authorities. In: LEVIFAUR, D. (Ed.). The handbook on the politics of regulation. Edward Elgar Publishing, Northampton, USA: 2011. p. 201-214. 
GUARDIANCICH, I.; GUIDI, M. Formal independence of regulatory agencies and varieties of capitalism: a case of institutional complementarity? Regulation \& Governance, v. 10, p. 211-229, set. 2016.

HORWITZ, R. B. The irony of regulatory reform: the deregulation of American telecommunications. New York/Oxford: Oxford University Press, 1989.

JORDANA, J.; LEVI-FAUR, D. The diffusion of regulatory capitalism in Latin America - sectoral and national channels in the making of new order. The ANNALS of the American Academy of Political and Social Science, v. 598, n. 1, p. 102-124, mar. 2005. KRAUSE, G. A.; LeWIS, D. E.; DouglAS, J. W. Political appointments, civil service systems, and bureaucratic competence: organizational balancing and executive branch revenue forecasts in the American States. American Journal of Political Science, v. 50, n. 3, p. 770-787, jul. 2006.

LEVY, B.; SPILLER, P. T. The institutional foundations of regulatory commitment: a comparative analysis of telecommunications regulation. The Journal of Law, Economics \& Organization, Oxford University Press, v. 10, n. 2, p. 201-246, 1994.

LEVI-FAUR, D. The politics of liberalisation: privatisation and regulation-for competition in Europe's and Latin America's telecoms and electricity industries. European Journal of Political Research, v. 42, p. 705-740, 2003.

LODGE, M. Accountability and transparency in regulation: critiques, doctrines and instruments. In: JoRdANA, J.; LEVI-FAUR, D. (Eds.). The Politics of Regulation, CRC series on competition, regulation and development. Cheltenham: Edward Elgar Publishing, 2004. p. 124-144. ISBN 1843764644.

MACEY, J. R. Organizational design and political control of administrative agencies. Journal of Law, Economics, e Organization, v. 8, n. 1, Conference on the Economics and Politics of Administrative Law and Procedures (mar. 1992), Oxford University Press, Oxford, p. 93-110, 1992.

MAgGetTI, M. De facto independence after delegation: a fuzzy-set analysis. Regulation \& Governance, v. 1, n. 4, p. 271-294, 2007. DOI: 10.1111/j.17485991.2007.00023.

MAHONEY, J.; THELEN, K. Explaining institutional change: ambiguity, agency and power. Cambridge: Cambridge University Press, 2010.

MAJONe, G. The regulatory State and its legitimacy problems. Political Science Series, Institute for Advanced Studies, Vienna, Austria, n. 56, jul. 1998. [Working Paper] $30 \mathrm{p}$.

MARCH, J.; OLSEN, J. Rediscovering institutions. The organizational basis of politics. Nova York: The Free Press, 1989.

Ministério da Administração e Reforma do Estado (MARE). Plano diretor da reforma do aparelho do Estado. Brasília, DF, 1995.

Mediano, A. P. Agencies' formal independence and credible commitment in the Latin American regulatory state: a comparative analysis of 8 countries and 13 sectors. Regulation \& Governance, 2018. Disponível em: <https://onlinelibrary. wiley.com/doi/abs/10.1111/rego.12187>. Acesso em: 21 fev. 2018. 
MitNICK, B. M. Origin of the theory of agency: an account by one of the theory's originators. Social Science Research Network, mar. 2013. Disponível em: <http:// papers.ssrn.com/sol3/papers.cfm?abstract_id=1020378>. Acesso em: 2 set. 2016.

Mueller, B.; PereirA, C. Credibility and the design of regulatory agencies in Brazil. Brazilian Journal of Political Economy, São Paulo, v. 22, n. 3(87), p. 65-88, jul.-set. 2002.

NoRTH, D. C. Institutions. Journal of Economic Perspectives, v. 5, n. 1, p. 97-112, Winter 1991.

NUNES, R.; NUNES, S. B.; REgO, G. A New governance model for regulatory independent agencies. Theoretical Economics Letters, v. 5, p. 4-13, 2015. Disponível em: <http://file.scirp.org/pdf/TEL_2015011917381643.pdf>. Acesso em: 17 jun. 2016.

Organisation for ECONOMIC Co-Operation and DeVElopment (OECD). The OECD Report on Regulatory Reform: synthesis. Paris: OECD, 1997.

. Working party on regulatory management and reform. Designing independent and accountable regulatory authorities for high quality regulation. Paris: OECD, 2005. 236 p.

OLSEN, J. P. Democratic government, institutional autonomy and the dynamics of change. West European Politics Journal, v. 32, n. 3, p. 439-465, 2009.

Ostrom, E. Governing the commons: the evolution of institutions for collective action. New York, NY: Cambridge University Press, 1990.

Pereira, C. E.; Mueller, B. Uma teoria da preponderância do Poder Executivo: o sistema de comissões no Legislativo brasileiro. Rev. bras. Ci. Soc. [online], v. 15, n. 43, p. 45-67, 2000. ISSN 0102-6909. Acesso em: 10 nov. 2014.

PESSOA, L. R. A natureza jurídica das "taxas de fiscalização" cobradas por agências reguladoras federais brasileiras. Âmbito Jurídico, Rio Grande, v. X, n. 47, nov. 2007. Disponível em: <https://ambitojuridico.com.br/cadernos/direito-tributario/anatureza-juridica-das-taxas-de-fiscalizacao-cobradas-por-agencias-reguladorasfederais-brasileiras/>. Acesso em: 4 de abril de 2018.

PIRES, J. C. L.; GoldSTEIN, A. Agências reguladoras brasileiras: realidade e desafios. Revista do BNDES, Rio de Janeiro, v. 8 n. 16, p. 3-41, dez. 2001.

Pó, M. V. O jogo regulatório brasileiro: a estabilidade contratual para além da autonomia das agências. Tese (Doutorado em Administração Pública e Governo). São Paulo: Fundação Getúlio Vargas, 2009. 217 f.

PRADO, M. M. The challenges and risks of creating independent regulatory agencies: a cautionary tale from Brazil. Vanderbilt Journal of Transnational Law, v. 41, p. 435503, 2008.

PRADO. Presidential dominance from a comparative perspective: the relationship between the executive branch and regulatory agencies in Brazil. In: Rose-ACKERMAN, S; LINDSETH, P. (Eds.). Comparative Administrative Law. Northampton, USA. Edward Elgar, 2010. 24 p. Disponível em: <https://papers.ssrn.com/sol3/papers. cfm?abstract_id=1690815>. Acesso em: 21 jun. 2017. 
Prakash, A.; Potoski. M. Dysfunctional institutions? Towards a new agenda in Governance studies. Regulation e Governance, v.10, p. 115-125, 2016.

SANTOS, L. A. Eficiência e eficácia de sistemas de regulação: o caso brasileiro. In: CONGRESO INTERNACIONAL DEL CLAD SOBRE LA REFORMA DEL ESTADO Y DE LA AdMINISTRACIÓN PÚBLICA, 10., 18-21 out. 2005, Santiago, Chile. Anais... Santiago: Clad, 2005. Disponível em http://www.clad.orgl.ve/fulltext/0052427.pdf> Acesso em 8 mar. 2017.

SMITH, W. Utility regulator: the independency debate. Public policy for private sector, Note no 127, oct. 1997. The World Bank Group. Washington DC. 4 p.

SPILleR, P. T.; TOMMASI, M. The institutional foundations of public policy: a transactions approach with application to Argentina. The Journal of Law, Economics e Organization, Oxford University Press, v.. 19, n. 2, p. 281-306, 2003.

THELEN, K. Varieties of capitalism: trajectories of liberalization and the new politics. Annual Review of Political Science, v. 15, p. 137,159, 2012.

TRILLAS, F.; MONTOYA, M. A. Independent regulators: theory, evidence and reform proposals. Info, v. 15, n. 3, p. 39-53, 2013. https://doi. org/10.1108/14636691311327115

VELASCO JUNIOR, L. A política pública de privatização no presidencialismo de coalizão brasileiro. Tese (Doutorado em Ciência Política). Instituto Universitário de Pesquisas do Rio de Janeiro. Rio de Janeiro, 2005. 285 f.

WORLD BANK. Regulatory governance in developing countries. Better regulation for growth: governance framework and tools for effective regulatory reform. Washington: The World Bank Group, 2010. 50 p.

YESILKAGIT, K.; CHRISTENSEN, J.G. Institutional design and formal autonomy: political versus historical and cultural explanations. Journal of Public Administration and Research Theory, v. 20, n. 1, p. 53-74, 2010. 


\section{Apêndice A-Agências reguladoras - aspectos relevantes da independência formal}

\begin{tabular}{|c|c|c|c|}
\hline Parâmetro & $\begin{array}{l}\text { Aneel (Lei, no } \\
9.427 / 1996)\end{array}$ & $\begin{array}{l}\text { Anatel (Lei no } \\
9.472 / 1997)\end{array}$ & $\begin{array}{l}\text { ANP (Lei no } \\
9.478 / 1997 \text { ) }\end{array}$ \\
\hline $\begin{array}{l}\text { Alcance e } \\
\text { estabilidade das } \\
\text { competências }\end{array}$ & $\begin{array}{l}\text { Exercia } \\
\text { competências de } \\
\text { órgão regulador e } \\
\text { poder outorgante. } \\
\text { Em } 1998 \text { passou } \\
\text { a atuar como } \\
\text { órgão de defesa } \\
\text { da concorrência } \\
\text { (Lei 9.648). Em } \\
2004 \text { deixou de ser } \\
\text { poder outorgante, } \\
\text { podendo atuar sob } \\
\text { delegação (Lei no } \\
\text { 10.848). }\end{array}$ & $\begin{array}{l}\text { Responsável pela } \\
\text { elaboração do } \\
\text { planejamento } \\
\text { de médio prazo } \\
\text { (planos de outorgas } \\
\text { e de metas de } \\
\text { universalização } \\
\text { dos serviços); } \\
\text { competência para } \\
\text { regular todos os } \\
\text { aspectos relevantes } \\
\text { da prestação dos } \\
\text { serviços. Texto } \\
\text { original preservado. }\end{array}$ & $\begin{array}{l}\text { Órgão regulador, } \\
\text { mas com atribuição } \\
\text { de representar } \\
\text { os interesses da } \\
\text { União nos contratos } \\
\text { de Concessão da } \\
\text { exploração de } \\
\text { petróleo. Recebeu } \\
\text { competências } \\
\text { relacionadas ao } \\
\text { biodiesel (Leis no } \\
\text { 11.097 e no 11.116) } \\
\text { e ao gás natural (Lei } \\
\text { no11.909). }\end{array}$ \\
\hline $\begin{array}{l}\text { Autonomia } \\
\text { administrativa e } \\
\text { de gestão }\end{array}$ & $\begin{array}{l}\text { Autonomia } \\
\text { limitada pela } \\
\text { obrigatoriedade } \\
\text { de celebração de } \\
\text { contratos de gestão. } \\
\text { Até 2000, poderia } \\
\text { ter diretores } \\
\text { exonerados sem } \\
\text { motivação, nos } \\
\text { primeiros quatro } \\
\text { meses de mandato } \\
\text { (revogado pela Lei } \\
\text { no 9.986). }\end{array}$ & $\begin{array}{l}\text { Garantias para } \\
\text { o exercício } \\
\text { das atividades } \\
\text { regulatória e } \\
\text { fiscalizatória, } \\
\text { conforme os } \\
\text { preceitos da } \\
\text { boa governança } \\
\text { regulatória. }\end{array}$ & $\begin{array}{l}\text { Garantias para } \\
\text { o exercício } \\
\text { das atividades } \\
\text { regulatória e } \\
\text { fiscalizatória, } \\
\text { conforme os } \\
\text { preceitos da } \\
\text { boa governança } \\
\text { regulatória, mas tem } \\
\text { a imparcialidade } \\
\text { comprometida } \\
\text { por representar os } \\
\text { interesses da União } \\
\text { nos contratos de } \\
\text { concessão. }\end{array}$ \\
\hline $\begin{array}{l}\text { Autonomia } \\
\text { financeira }\end{array}$ & $\begin{array}{l}\text { Lei não é incisiva a } \\
\text { esse respeito. }\end{array}$ & $\begin{array}{l}\text { Dois dispositivos } \\
\text { legais: o } \S \\
\text { 20 do art. } 8 \text { o } \\
\text { (autarquia especial } \\
\text { caracterizada } \\
\{\ldots \text {...\} e autonomia } \\
\text { financeira), e no } \\
\text { inciso XXI do art. } 19 \\
\text { (competência para } \\
\text { arrecadar e aplicar } \\
\text { suas receitas). }\end{array}$ & $\begin{array}{l}\text { Lei não é incisiva a } \\
\text { esse respeito. }\end{array}$ \\
\hline
\end{tabular}




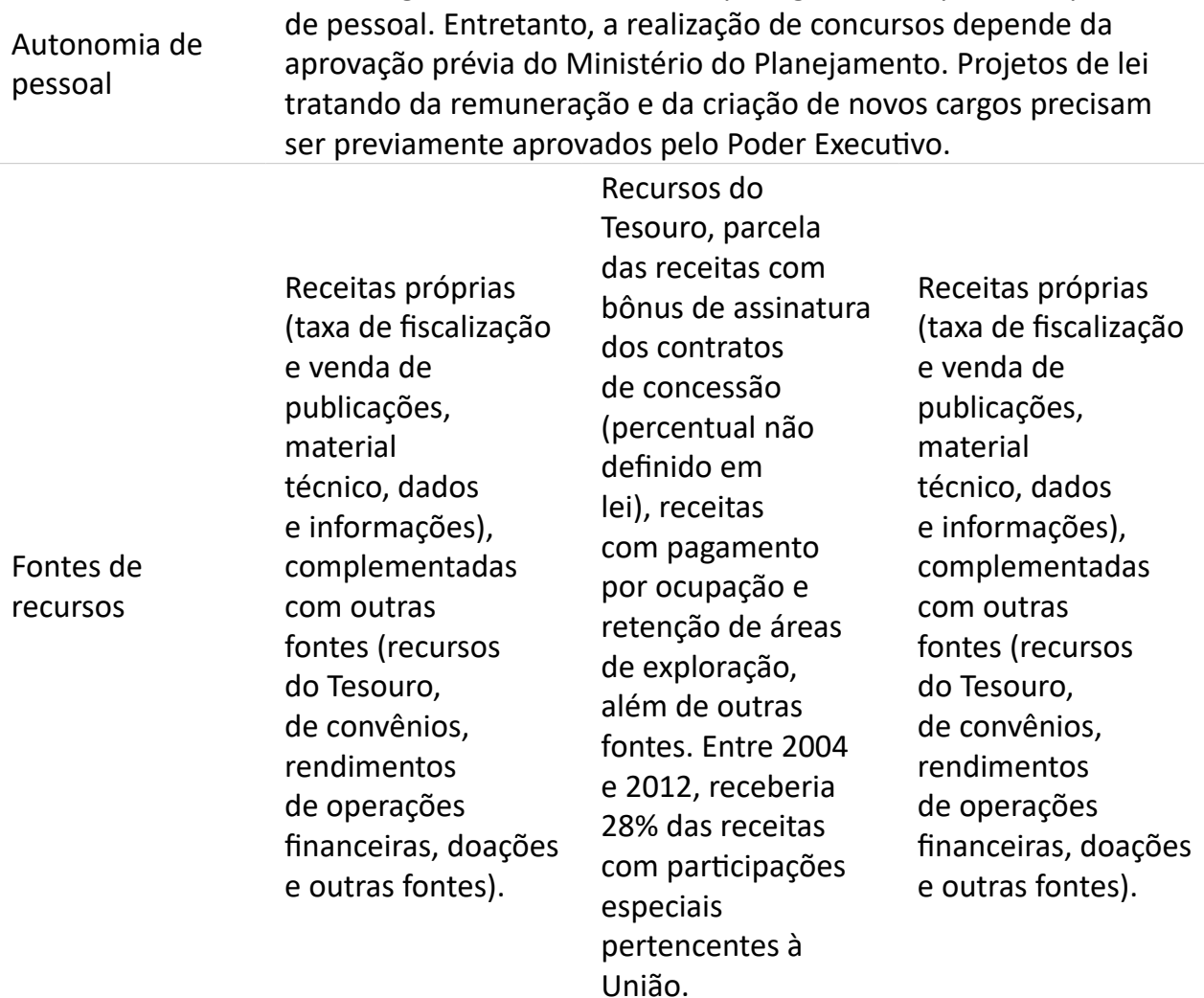

As três agências têm autonomia para gerir os respectivos quadros de pessoal. Entretanto, a realização de concursos depende da aprovação prévia do Ministério do Planejamento. Projetos de lei tratando da remuneração e da criação de novos cargos precisam ser previamente aprovados pelo Poder Executivo.

Recursos do das receitas com bônus de assinatura taxa de fiscalização e venda de publicações, écnico, dados informações) complementadas com outras fontes (recursos do Tesouro, de convênios, rendimentos de operações inanceiras, doações União.

Fontes: elaboração própria, a partir da consulta às leis de criação das três agências e alterações posteriores. 
Apêndice B - Evolução da relação entre receitas e despesas e do contingenciamento orçamentário das agências reguladoras entre 1998 e2017

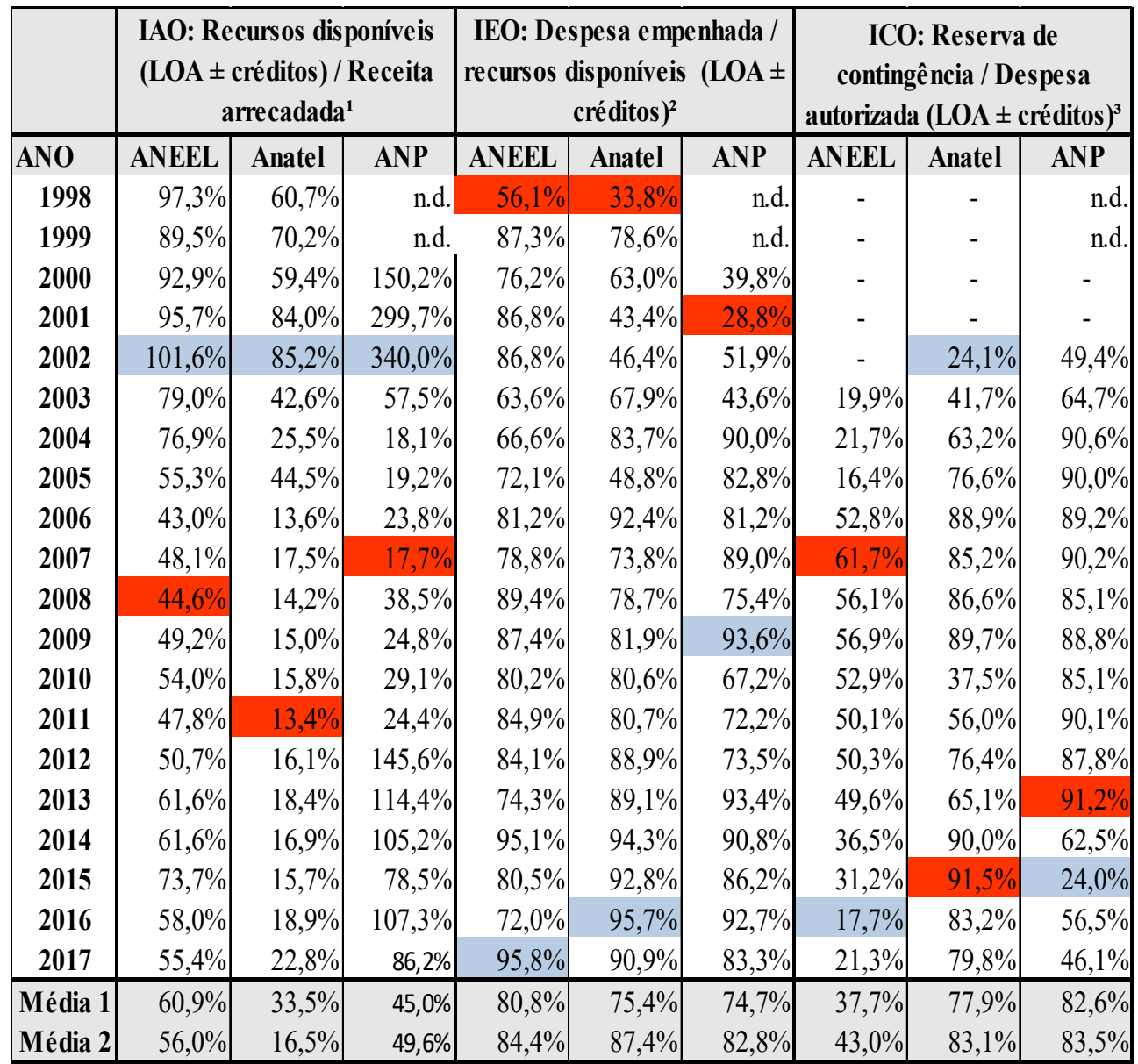

(1) Relação entre a a despesa autorizada (sem as reservas de contingência) e arrecadação própria (taxas de fiscalização e outras receitas previstas em lei); (2) Relação entre despesa executada (considera efeitos dos decretos de contingenciamento) e 0 autorizado pela Lei Orçamentária Anual; e, (3) Contingenciamentos previstos na própria Lei Orçamentária Anual. Média 1 = média da série histórica. Média 2 = média dos últimos dez anos.

Fonte: elaboração própria a partir de relatórios fornecidos pelas agências reguladoras. 
Apêndice C - Estimativa dos índices de independência formal (IIF) e de facto

\begin{tabular}{|c|c|c|c|c|c|c|c|}
\hline \multirow[t]{2}{*}{ Dimensão/indicador } & \multirow[t]{2}{*}{ Pesos } & \multicolumn{3}{|c|}{ IIF } & \multicolumn{3}{|c|}{$\begin{array}{c}\text { Índice de } \\
\text { independência de } \\
\text { facto }\end{array}$} \\
\hline & & Aneel & Anatel & ANP & Aneel & Anatel & ANP \\
\hline $\begin{array}{l}\text { Status do Diretor-Geral da } \\
\text { Agência }\end{array}$ & 0,20 & 0,144 & 0,151 & 0,144 & 0,144 & 0,151 & 0,144 \\
\hline \multicolumn{8}{|l|}{ Tempo de mandato } \\
\hline 8 anos ou mais & 1,00 & & & & & & \\
\hline De 6 a 8 anos & 0,80 & & & & & & \\
\hline 5 anos & 0,60 & & & & & & \\
\hline 4 anos & 0,40 & & & & & & \\
\hline $\begin{array}{l}\text { Menor que } 4 \text { anos, fixado } \\
\text { por quem indica }\end{array}$ & 0,20 & $\mathrm{x}$ & $x$ & $x$ & $x$ & $x$ & $x$ \\
\hline Ausência de mandato fixo & 0,00 & & & & & & \\
\hline
\end{tabular}

Quem indica o Diretor-

Geral?

Os membros do Conselho

de Administração

1,00

Compartilhado entre

0,75

Parlamento e Governo

O Parlamento

$$
0,50
$$

0,25

O Governo, coletivamente

0,00

Um ou dois ministérios

\section{Demissão}

Impossível

$$
1,00
$$

Possível, mas não por razões políticas

0,66

Ausência de regras claras

$\begin{array}{llllllll}0,33 & x & x & x & x & x & x\end{array}$

A critério de quem indica ${ }^{2}$

0,00 
Diretor pode ocupar

outros cargos no

Governo?

Não é permitida

$$
1,00
$$

Somente se permitida pelo

Governo

$\begin{array}{lllllll}0,50 & x & x & x & x & x & x\end{array}$

Sim, sem normas

0,00

específicas a respeito

0 mandato pode ser renovado?

Não

$$
1,00
$$

Sim, mas somente uma

vez.

$$
0,50
$$

Sim, mais de uma vez.

$\begin{array}{lllllll}0,00 & x & x & x & x & x & x\end{array}$

Independência é requisito

para a indicação?

Sim

$$
1,00
$$

Não

0,00

$\begin{array}{llllll}x & x & x & x & x\end{array}$

Status do Conselho de

Administração

0,20

0,144

0,151

$0,144 \quad 0,144$

0,151

0,144

Tempo de mandato

8 anos ou mais

De 6 a 8 anos

$$
0,80
$$

5 anos

$$
0,60
$$

4 anos

Menor que 4 anos, fixado por quem indica

$$
0,40
$$

Ausência de mandato fixo

$0,20 \quad x \quad x \quad x \quad x \quad x$

0,00 
Quem indica os membros?

Os membros do Conselho

de Administração

1,00

Compartilhado entre

0,75

Parlamento e Governo

0,50

O Parlamento

\section{0,25}

O Governo, coletivamente

0,00

Um ou dois ministérios

\section{Demissão}

Impossível

Possível, mas apenas por

razões não relacionadas às

0,67

políticas

Ausência de regras claras

$0,33 \quad x \quad x \quad x \quad x \quad x \quad x$

A critério de quem indica ${ }^{2}$

$$
0,00
$$

Membro pode ocupar

outros cargos no

\section{Governo?}

Não é permitida

Somente se permitida pelo

Governo

1,00

$\begin{array}{lllllll}0,50 & X & X & X & x & x & X\end{array}$

Sim, sem normas

0,00

específicas a respeito

0 mandato pode ser renovado?

Não

$$
1,00
$$

Sim, mas somente uma

vez.

$$
0,50
$$

Sim, mais de uma vez.

$$
0,00
$$

Independência é requisito para a indicação?

Sim

1,00

Não

0,00

X $\quad X \quad X \quad X \quad X$


Relacionamento com

o Governo e com o

0,20

0,083

0,167

0,150

0,083

$0,167 \quad 0,150$

Parlamento

Independência

é formalmente

estabelecida?

Sim

1,00

Não

$0,00 \quad x$

$x$

$x$

Quais as obrigações

perante o Governo?

Não há.

Apenas relatório anual de

1,00

prestação de contas.

0,67

Relatório anual de

prestação de contas

precisa ser aprovado.

0,33

$x$

$x \quad x$

$x$

Agência deve prestar

contas de todos os atos.

Quais as obrigações

perante o Governo?

Não há.

Apenas relatório anual de

1,00

prestação de contas.

0,67

Relatório anual de prestação de contas precisa ser aprovado.

\section{0,33}

$x$

$\mathrm{X}$

0,00

$x$

$x$

$x \quad x$

$x$

$x$

Agência deve prestar

0,00

contas de todos os atos. 
Que outro órgão, além do

Judiciário, pode reverter

decisões da Agência,

quando ela detém

competência exclusiva?

Nenhum
Uma estrutura
1,00
especializada
0,75
O Governo, com
qualificações
0,5
0,00
O Governo,

incondicionalmente.

\begin{tabular}{|c|c|c|c|c|c|c|}
\hline $\begin{array}{l}\text { lomia financeira e } \\
\text { izacional }\end{array}$ & 0,20 & 0,117 & 0,200 & 0,092 & 0,067 & 0,067 \\
\hline
\end{tabular}

Quais as fontes de orçamento da Agência?

Taxas de fiscalização sobre

a indústria regulada.

1,00

Recursos públicos e taxas

$0,50 \quad x \quad x$

de fiscalização.

0,00

$\mathrm{X}$

O Governo.

Como o orçamento é controlado?

Pela Agência.

$$
1,00
$$

Por um órgão de contas ou

o Judiciário.

0,67

A Agência e o Governo.

0,33

Somente o Governo.

0,00

$x$

$\begin{array}{llll}X & X & X & X\end{array}$

Quem decide sobre a

estrutura interna?
A Agência
1,00
A Agência e o Governo
0,50
$x$
O Governo.
0,00 


\section{Quem é encarregado da política de pessoal da Agência (contratar, demitir e decidir sobre a alocação)?}

1,00

0,50
$X$

$\begin{array}{lrrrrrrr}\text { A Agência e o Governo. } & 0,50 & & & X & & \text { X } \\ \text { O Governo } & 0,00 & & & X & & X & \text { X } \\ \text { Competências regulatórias } & \mathbf{0 , 2 0} & \mathbf{0 , 0 5 0} & \mathbf{0 , 1 5 0} & \mathbf{0 , 1 0 0} & \mathbf{0 , 0 5 0} & \mathbf{0 , 0 5 0} & \mathbf{0 , 0 5 0}\end{array}$

Somente a Agência.

$\begin{array}{ll}\text { A Agência e outras } & 1,00 \\ \text { autoridades } & \\ \text { independentes. } & 0,75\end{array}$

A Agência e o Parlamento. $\quad 0,50$

A Agência e o Governo. $\quad 0,25$

A Agência tem

(n)

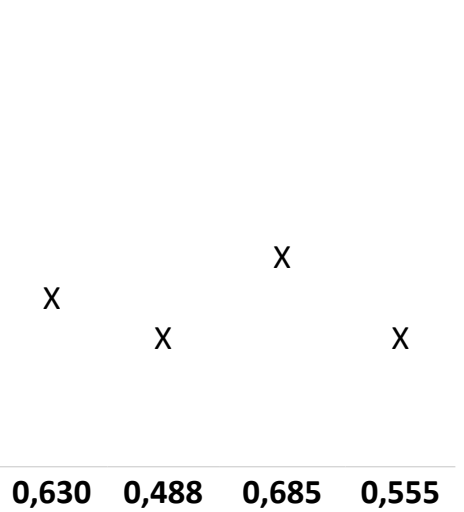

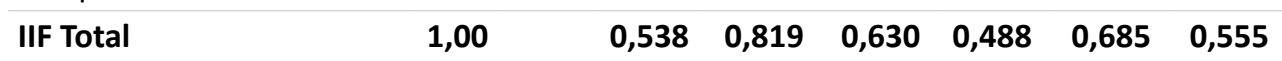

Fonte: elaboração própria, conforme metodologia proposta por Gilardi (2002). Nota: os índices de independência de facto foram estimados a partir de ajustes nos escores de alguns indicadores do IIF, nas dimensões "autonomia financeira e organizacional" e "competências regulatórias".

\section{José Nilton de Souza Vieira}

Programa de Pós-Graduação em Administração (UnB). Doutor em Administração Pública pela Universidade de Brasília. Mestre em economia pela Universidade Federal do Rio de Janeiro. Graduado em Economia pela Universidade Federal de Viçosa. Especialista em Políticas Públicas e Gestão Governamental. josensv@gmail.com. http://lattes.cnpq.br/9360834697110207

\section{Ricardo Corrêa Gomes}

Universidade de Brasília (UnB). Pos-doutor em Public Management pela Georgia State University. Doutor em Administração Pública pela Aston University, Inglaterra. Mestre em administração Pública pela Escola Brasileira de Administração Pública e Empresas. Bolsista de Produtividade em Pesquisa do Conselho Nacional de Desenvolvimento Científico e Tecnológico. ricardo.gomes@fgv.br http://lattes.cnpq.br/3539564256173485

\section{Edson Ronaldo Guarido Filho}

Universidade Federal do Paraná (UFPR). Economista pela Universidade de São Paulo Mestre e Doutor em Administração pela Universidade Federal do Paraná. Professor do Programa de Pós-Graduação em Gestão da Informação da Universidade Federal do Paraná. Professor do Programa de Pós-Graduação em Administração da Universidade Positivo. Pesquisador Colaborador da Universidade de Brasília. Bolsista do Conselho Nacional de Desenvolvimento Científico e Tecnológico. edson.guarido@gmail.com http://lattes.cnpq.br/2435628775717990 